\title{
ANALYSIS OF DENTAL GOLD ALLOYS
}

\author{
By William H. Swanger
}

\begin{abstract}
AESTPACT
Complete chemical analyses of about 40 dental gold alloys were made as part of the investigation of their physical properties. These analyses required the determination of silver, gold, platinum, palladium, iridium, rhodium, copper, zine, nickel, tin, manganese, iron, and magnesium. Methods as found in the literature for the determination of the above-named metals were modified so as to give accurate results when applied to alloys of this type. New methods were developed for the determination of tin and iridium. Many analyses of mixtures of known composition are given to show the degree of accuracy of the methods used. These methods are assembled in a detailed procedure for the complete analysis of dental gold alloys. The composition of 13 typical alloys is given in a table.
\end{abstract}

\section{CONTENTS}

$\begin{array}{ll}\text { Page } & \text { Introduction } \\ \text { I. } & 210\end{array}$

II. Sampling

III. Reagents _._.

IV. Qualitative examination $\ldots \ldots \ldots \ldots \ldots \ldots$

1. Detection of silver and iridium. 212

2. Detection of tin and iron

3. Detection of gold................... 214

4. Detection of copper............ 214

5. Detection of platinum, palladium, and rhodium $\ldots \ldots \ldots$

6. Detection of nickel, manganese, zinc, and magnesium_... 216

V. Determination of silver..................... 217

VI. Determination of iridium .

VII. Determination of tin

VIII. Determination of gold _._.

IX. Determination of palladium 228

X. Determination of copper

XI. Determination of platinum

XII. Determination of rhodium

XIII. Determination of zinc

XIV. Determination of nickel_._. 235

XV. Determination of manganese...... 236

XVI. Determination of iron_... 237

XVII. Determination of magnesium .

XVIII. Results of analyses of a number of alloys_.

XIX. Acknowledgment. $101336^{\circ}-26$ 


\section{INTRODUCTION}

The study of the properties of dental gold alloys has been an important part of the general research on dental materials begun several years ago at the Bureau of Standards in cooperation with the Weinstein Research Laboratories. ${ }^{1}$ In conducting this work on the alloys it became necessary to determine their chemical compositions. About 40 alloys were analyzed by the author while employed by the Weinstein Research Laboratories as a research associate. The purpose of this paper is to describe the methods used and to assemble them in a complete procedure for the analysis of materials of this kind.

Dental gold alloys are, in general, composed chiefly of gold, silver, copper, and platinum. The proportionate amounts of these metals are usually of the order of 60 per cent of gold, 10 to 15 per cent of silver, 10 to 15 per cent of copper, and 10 per cent of platinum. Palladium is often substituted for part or all of the platinum. Many alloys contain small amounts of iridium and occasionally one is found to contain rhodium. Of the base metals besides copper, small amounts of nickel, manganese, zinc, and tin are found in many of the alloys and occasionally iron and magnesium occur. As many as nine of the above-named metals have been found in a single alloy. A number of these were undoubtedly present as impurities in the major constituents.

No procedure for the complete analysis of such alloys is giren in the literature. Many of the methods given for the determination of the noble metals proved to be inaccurate when applied to these alloys and had to be modified. A new method was used for the determination of iridium. For the determination of the base metals it was found possible to adapt methods that are in general use, except that a new method was devised for the determination of tin.

In connection with the study of the physical properties of dental gold alloys, it was desirable to determine their composition with the highest possible accuracy. This procedure was, therefore, developed with that end in view. Many of the details of the procedure can be omitted when the accurate determination of all the constituents of the alloy is not required, as, for example, in control analyses. The various steps of the procedure are discussed in the order in which they would generally be carried out in making a complete analysis.

\section{SAMPLING}

The alloys submitted for analysis are usually in the form of wires, bands, or plates. These should be rolled out on a pair of hand rolls to a ribbon or sheet 0.003 to 0.005 inch thick. These rolled pieces

1 Dental research. J. Am. Dental Assn., 11, p. 249; 1924. Physical properties of dental materials (wrought gold alloys), by R. L. Coleman, jr., J. Am. Dental Assn., 12, p. 520; 1925. 
are then clipped to short lengths or small squares one-sixteenth to one-cight of an inch in size. Uniform and representative samples may then be obtained by selecting at random a suitable number of these small pieces.

It is often advisable to make a qualitative examination of the sample before procecling with the quantitative determinations. A sample of about $1 \mathrm{~g}$ is usually sufficient for this. For the quantitative analysis a weight of sample should be chosen that will contain enough of the minor constituents for their determination with sufficient precision and still not contain inconveniently large amounts of the major constituents. For most alloys $2 \mathrm{~g}$ is a convenient weight of sample.

\section{REAGENTS}

The following reagents are used at the concentrations described below, unless otherwise stated in the text:

Sulphuric acid (sp. gr. 1.84).

Nitric acid (sp. gr. 1.42).

Hydrochloric acid (sp. gr. 1.18).

Dilute sulphuric acid. -1 volume of sulphuric acid, 1 volume of water.

Ditute nitric acid. -1 volume of nitric acid, 1 volume of water.

Ditute hydrochloric acid.-1 volume of hydrochloric acid, 1 volume of water.

One per cent sulphuric acid.-1 cc of sulphuric acid, 99 cc of water.

One per cent nitric acid.-1 cc of nitric acid, $99 \mathrm{cc}$ of water.

One per cent hydrochloric acid.-1 cc of hydrochloric acid, $99 \mathrm{cc}$ of water.

Aqua regia. -4 volumes of hydrochloric acid, 1 volume of nitric acid, 1 volume of water.

Ditute aqua regia. -4 volumes of hydrochloric acid, 1 volume of nitric acid, 6 volumes of water.

Ammonium hydroxide (sp. gr. 0.90).

Dilute ammonium hydroxide.-1 volume of ammonium hydroxide, 1 volume of water.

Strong sodium hydroxide solution. $-50 \mathrm{~g}$ of sodium hydroxide sticks, 100 cc of water.

Dimethylglyoxime solution. -1 g of dimethylglyoxime, $100 \mathrm{cc}$ of 95 per cent ethyl alcohol.

Ammonium thiocyanate, 4 per cent solution. $-4 \mathrm{~g}$ of ammonium thiocyanate, $100 \mathrm{cc}$ of saturated solution of sulphur dioxide in water.

Sodium acetate solution (used for the precipitation of tin).- This solution is prepared by adding $300 \mathrm{~g}$ of sodium bicarbonate to about $205 \mathrm{cc}$ of glacial acetic acid and diluting the solution to $900 \mathrm{cc}$. The final solution should give an acid reaction with methyl red. Three cc of this solution contains $1 \mathrm{~g}$ of sodium acetate. 
Ammonium acetate solution (used for the precipitation of tin).This solution is prepared by nearly neutralizing $250 \mathrm{cc}$ of glacial acetic acid with ammonium hydroxide and diluting the solution to 1,000 cc. The final solution should give an acid reaction with methyl red. Three cc of this solution will contain approximately $1 \mathrm{~g}$ of ammonium acetate.

Many of the precipitates obtained in these analyses are finely divided and have a tendency to pass through eren the tightest filter papers. Such precipitates can be held on the paper if it is first treated with a suspension of finely divided filter-paper pulp. This may be prepared by digesting several $15 \mathrm{~cm}$ pieces of ashless filter paper with 300 to $400 \mathrm{cc}$ of distilled water in an Erlenmeyer flask and then shaking vigorously until the paper is disintegrated. Enough of this suspension is poured on the filter after it is fitted in the funnel to fill the paper to the rim. After the water has drained off the filter is ready to use.

\section{QUALITATIVE EXAMINATION}

A careful qualitative examination of the sample is necessary for the detection of the minor constituents. The presence of the major constituents usually becomes evident during the search for the minor constituents. Only those metals which were mentioned before as having been found in dental gold alloys will be considered here, namely, gold, silver, platinum, and copper as major constituents; and palladium, iridium, rhodium, tin, nickel, manganese, zinc, iron, and magnesium as minor constituents.

\section{DETECTION OF SILVER AND IRIDIUM}

The sample is dissolved in 15 to 20 cc of dilute aqua regia. If silver is present, the silver chloride that forms on the surface of the pieces of the sample is broken off from time to time with a glass rod. The action of the acid is hastened by heating on the steam bath. When all of the metallic portion of the sample has been dissolved the solution is diluted with water to about $200 \mathrm{cc}$ and allowed to stand on the steam bath until the silver chloride has settled out. The solution is then cooled and the silver chloride is filtered off on a paper. If iridium is present the silver chloride residue will be dark colored. When an alloy in which gold is the predominant metal and which contains iridium is dissolved in aqua regia, all of the iridium is left as an insoluble metallic residue. This will be more fully discussed under the section devoted to the quantitative determination of iridium.

The silver chloride residue should always be examined to determine whether or not it contains iridium. Hot, dilute ammonium hydroxide is poured through the paper on which the residue was filtered until 
all of the visible particles of silver chloride have dissolved. Any iridium that is present will be left as a black residue on the paper. Paper and residue are digested for 30 minutes on the steam bath in a small beaker with about 25 cc of dilute ammonium hydroxide. 'The paper pulp and residue are filtered off and washed thoroughly with hot water containing 3 to $4 \mathrm{cc}$ of ammonium hydroxide per liter. The paper is then burned off in a porcelain crucible. If there is no dark metallic residue in the crucible, iridium is not present in the alloy.

If there is no silver in the alloy, the aqua regia solution of the sample should be carefully filtered through a small paper that has first bcen treated with filter-paper pulp. The paper is burned off and iridium, if present in the sample, will be left as a dark metallic residue.

To positively identify this residue as iridium, proceed as follows: Transfer the residue to a gold crucible. Add about $1 \mathrm{~g}$ of solid sodium hydroxide and $0.5 \mathrm{~g}$ of sodium nitrate and fuse the mixture at a low red heat for half an hour. Cool the melt and dissolve it out of the crucible with water. Make the solution acid with hydrochloric acid. Hydrochloric acid must not be added to the solution while it is in contact with the gold crucible. Evaporate almost to dryness. Then add 5 to $10 \mathrm{cc}$ of aqua regia and digest for half an hour. Filter off any unattacked residue. Add 10 to $15 \mathrm{cc}$ of saturated ammonium chloride solution and evaporate to dryness on the steam bath. Add the least amount of cold water necessary to dissolve the salts. Most of the iridium present will appear as very small, heavy, reddish-black crystals of ammonium chloroiridate on the bottom of the beaker. These crystals are quite distinctive in appearance. To further confirm the presence of iridium, evaporate the solution containing the crystals to dryness. Add sulphuric acid in slight excess over the amount required to convert the salts to sulphate. Heat on a hot plate until the sulphuric acid begins to fume. Cool and add a few drops of nitric acid. Upon reheating cautiously on the hot plate, an intense but fugitive blue color will appear in the mixture when as little as a few tenths of a milligram of iridium is present.

\section{DETECTION OF TIN AND IRON}

The aqua regia solution of the sample, after the silver chloride and iridium have been filtered off, is first examined for the presence of tin. If not more than $20 \mathrm{cc}$ of dilute aqua regia was used to dissolve the sample, 45 cc of sodium acetate solution, prepared as directed under Section III, Reagents, is added ${ }^{2}$ and the solution is digested for one hour on the steam bath. Tin, if present, will be

${ }^{2} \mathrm{About} 0.6 \mathrm{~g}$ of $\mathrm{NaC}_{2} \mathrm{H}_{3} \mathrm{O}_{2}$ should be added for each cc of dilute aqua regia used to dissolve the sample. See VII, Determiriation of tin. 
thrown down as a flocculent white precipitate. Any iron present in the sample will be precipitated as ferric hydroxide by this reagent. Hence, if the alloy contains tin and iron the precipitate obtained with sodium acetate may be brown. The precipitate is filtered off on a tight paper treated with filter-paper pulp. It is washed well, first with hot 1 per cent solution of sodium chloride, and then with hot 1 per cent solution of ammonium chloride. The ammonium chloride wash water must be kept separate from the main filtrate. If the presence of iron is suspected, a small portion of the precipitate is removed and treated with a little hydrochloric acid. The usual qualitative tests for the detection of small amounts of iron are applied to this solution. ${ }^{3}$

The remainder of the precipitate with the paper is ignited in a porcelain crucible. If iron is absent a white residue of stannic oxide is obtained. To further confirm the presence of tin, a small amount of potassium cyanide is melted in a porcelain crucible, the ignited residue is addêd, and the fusion continued for about 15 minutes. Tin, if present, will be reduced to a metallic globule, which is separated from the melt and identified as tin by the usual qualitative tests.

\section{DETECTION OF GOLD}

The solution of the sample from which silver, iridium, and tin have been removed is evaporated to dryness. About 5 ce of sulphuric acid is added to break up the acetate salts. The mixture is heated until all of the acetic acid has evaporated. About $5 \mathrm{cc}$ of aqua regia is added to redissolve any precipitated metals. The solution is diluted to about $50 \mathrm{cc}$ and saturated with sulphur dioxide. All of the gold will be precipitated in a finely divided metallic form. It is filtered off on a tight paper. The color of the ignited precipitate will serve to identify it as gold.

\section{DETECTION OF COPPER}

The filtrate from the precipitation of the gold, being still thoroughly saturated with sulphur dioxide, is treated with sodium hydroxide solution until it is just alkaline. It is then acidified with 9 to 10 drops of hydrochloric acid. Upon addition of sufficient ammonium thiocyanate all of the copper will be precipitated as white cuprous thiocyanate. $^{4}$ The precipitate is allowed to settle for sereral hours and is then filtered off on a tight paper treated with filter-paper pulp. The solution of the precipitate in dilute nitric acid may be used for further confirmation of the presence of copper.

\footnotetext{
Aluminum, if present in the alloy, will also be precipitated by the sodium acetate. A portion of the precipitate is removed and treated with hydrochloric acid, and the usual qualitative tests for the presence of aluminum are applied to the solution thus obtained.

- Swanger and Wichers, The analytical separation of copper from the platinum metals, J. Am. Chem. Soc., 46, p. 1814; 1924.
} 


\section{DETECTION OF PLATINUM, PALlADIUM, AND RHODIUM}

(a) Palladium.-The filtrate from the precipitation of the copper is evaporated to dryness. About 5 cc of nitric acid is earefully added to the dry salts to destroy the thiocyanate reagent. The nitric acid is then driven off by adding successive portions (about $5 \mathrm{cc}$ each) of hydrochloric acid and evaporating to dryness after each addition of acid. The residue is then taken up with $15 \mathrm{cc}$ of hydrochloric acid and diluted to about $250 \mathrm{cc}$. A fairly rapid stream of hydrogen sulphide is passed through the solution for half an hour while it is heated on the hot plate to incipient boiling. Platinum, palladium, and rhodium, if present, will all be precipitated as sulphides. The precipitated sulphides are filtered off and washed with hot water. The precipitate and paper are returned to the beaker and digested with $10 \mathrm{cc}$ of dilute aqua regia until all of the sulphides have dissolved. The paper pulp is filtered off. The solution is to be tested for the presence of palladium, platinum, and rhodium. A portion of the solution is removed, diluted to about $15 \mathrm{cc}$, and 5 to $10 \mathrm{cc}$ of a 1 per cent dimethylglyoxime solution is added. If palladium is present it will immediately form the characteristic lemon-yellow precipitate of palladium dimethylglyoxime. To confirm the presence of palladium, the precipitate is filtered off on a paper and washed well with hot water. The paper and precipitate are burned off and the residue is reduced to metal by heating in a porcelain crucible in an atmosphere of hydrogen. The metal is dissolved in a few drops of dilute aqua regia. The solution is evaporated to dryness several times with hydrochloric acid to drive off the nitric acid. The residue is taken up with a little water and a drop of hydrochloric acid. A few drops of a 1 per cent solution of potassium iodide added to this solution will form a dense black precipitate if palladium is present. This is a delicate test for small amounts of palladium.

(b) Platinum.-The remainder of the aqua regia solution of the sulphides, of which a portion was used in testing for palladium, is evaporated to dryness several times with hydrochloric acid to drive off the nitric acid. The residue is taken up with 10 to $15 \mathrm{cc}$ of water and 1 to $2 \mathrm{cc}$ of hydrochloric acid. About $10 \mathrm{cc}$ of a saturated solution of ammonium chloride is then added. Most of the platinum will be precipitated as yellow ammonium chloroplatinate. If nitric acid is present, palladium may also be precipitated as the red ammonium chloropalladate. If only a small amount of platinum is present, it may be necessary to evaporate the solution to dryness on the steam bath, after the addition of the ammonium chloride. By dissolving the salts in the least amount of cold water, the yellow crystals of the chloroplatinate can be detected on the bottom of the beaker, eren when as little as a milligram of platinum is present.

$101336^{\circ}-26-2$ 
A still more delicate test for the detection of platinum is the red color formed when potassium iodide is added to a dilute platinum chloride solution. The solution should first be freed of palladium and nitric acid, and should contain only a very slight amount of hydrochloric acid. A few drops of a 1 per cent solution of potassium iodide added to the cold platinum solution which should have a volume of about $5 \mathrm{cc}$, will produce a faint red color which upon standing for about half an hour develops to a deep red color when as little as a few tenths of a milligram of platinum is present.

(c) RHoDium.-The mother liquor from the precipitation of the platinum with ammonium chloride will contain most of the rhodium. The presence of rhodium is established by the rose-pink color of the solution. However, the presence of palladium may hide the pink color of the rhodium chloride. Hence, the solution must first be freed from palladium.

The amronium chloroplatinate is filtered off. The filtrate is evaporated almost to dryness on the steam bath. About $5 \mathrm{cc}$ of dilute nitric acid is added and the solution is digested until the red crystals of ammonium chloropalladate have settled out. It may be necessary to add more ammonium chloride during this treatment to make up for the loss of ammonium chloride by the action of the nitric acid. This red salt is filtered off. The rose-pink color of the filtrate indicates the presence of rhodium.

To further confirm the presence of rhodium, this solution is freed from nitric acid, and a stream of hydrogen sulphide gas is then passed through it while it is heated to incipient boiling. This will precipitate all of the rhodium, together with small amounts of platinum and palladium that were not precipitated by the ammonium chloride. The sulphides are filtered off, ignited in a porcelain crucible, and reduced to metal in a stream of hydrogen. The residue is then fused in a covered porcelain crucible with a few grams of potassium pyrosulphate for about half an hour at a red heat. When the melt is cooled it will have a pink color if the amount of rhodium present is not too large. The melt is dissolred in hot water. Two or three cc of hydrochloric acid and about $1 \mathrm{~g}$ of sodium chloride are added and the solution is evaporated to dryness. When the residue is taken up in water the characteristic rose-pink color of rhodium chloride can be seen.

\section{DETECTION OF NICKEL, MANGANESE, ZINC, AND MAGNESIUM}

All of the above-named base metals that are present in the sample are contained in the filtrate from the precipitation of platinum, palladium, and rhodium by hydrogen sulphide. Their presence or 
absence is determined by the methods generally used for the detection of these metals. ${ }^{5}$

\section{DETERMINATION OF SILVER}

With the exception of iron, manganese, and magnesium, all of the contituents of a dental gold alloy are usually determined in the same sample.

The sample is dissolved in dilute aqua regia in a 250 cc beaker covered with a watch glass and heated on the steam bath. Twentyfive ec of dilute aqua regia is sufficient to dissolve a $2 \mathrm{~g}$ sample. Silver chloride will be left as an insoluble residue, usually in the form of the small plates of the original sample. It should be broken up from time to time with a glass rod until the alloy is completely decomposed. If tin is present it is essential that the solution be not allowed to evaporate to dryness, as this will cause loss by volatilization of stannic chloride. When the alloy has been completely decomposed 150 to $200 \mathrm{cc}$ of water is added and the solution is digested on the steam bath for about one hour. It is then set aside to cool until the supernatant liquid is perfectly clear, when the silver chloride is filtered off.

If metals of the platinum group are present in the alloy, the silver chloride residue will be discolored by contamination with platinum metals and must be dissolved and reprecipitated. The procedure is as follows: Filter off the silver chloride on a paper and wash well with water. Pour hot dilute ammonium hydroxide on the paper in successive portions until no more of the silver chloride can be seen. If the resulting filtrate is not clear pour it back on the paper until it runs through clear. If iridium is present it will be left as a black metallic residue on the paper. Any platinum or palladium that was present will be in solution along with the silver chloride. Wash the residue several times with hot 1 per cent ammonium hydroxide. Place paper and residue in a small beaker, add 15 to 25 cc of dilute ammonium hydroxide, and digest for half an hour on the steam bath. Filter through a small paper and wash well with hot 1 per cent ammonium hydroxide. Transfer the paper and residue to a weighed porcelain crucible for the determination of iridium. Unite the two ammoniacal filtrates and acidify with nitric acid to reprecipitate the silver chloride. This is filtered off on a Gooch crucible, washed well with water, dried at $110^{\circ} \mathrm{C}$., and weighed.

The platinum and palladium contained in the filtrate from the reprecipitation of the silver chloride are recovered and added to the main solution of the sample; that is, to the filtrate from the first precipitate

\footnotetext{
- Cadmium, although not encountered in any of the alloys that were analyzed in this investigation, may beamong the constituents of dental gold alloys. In following the scheme outlined above some of it may be precipitated by hydrogen sulphide along with the platinum, but at the acidity used for this precipitation some of the cadmium will remain in the filtrate. By adjusting the acidity of this filtrate to $0.01 \mathrm{~N}$ with respect to sulphuric acid the cadmium will be precipitated along with zinc by hydrogen sulphide. Tho yellow color of the sulphide will serve as an indication of the presence of cadmium.
} 
of silver chloride. The procedure is as follows: Evaporate the filtrate from the reprecipitation of the silver chloride to dryness. Destroy the ammonium nitrate by cautiously adding hydrochloric acid. Evaporate the residue to a small volume and transfer to a porcelain crucible. Continue the evaporation to dryness in the crucible and then add about $10 \mathrm{~g}$ of sodium pyrosulphate. Fuise the mixture for about half an hour at a red heat, cool, and dissolve the melt in hot water. Pass hydrogen sulphide through the solution for about half an hour while it is heated to incipient boiling on the hot plate. Filter off the precipitated platinum and paliadium sulphides, wash, and ignite to metal in a porcelain crucible. Dissolve the residue in the crucible in a few cc of dilute aqua regia, filter off any silica, and add the solution to the main portion of the sample before the determination of platinum or palladium is made. This rather tedious procedure for the recovery of platinum and palladium is made necessary by the fact that these metals are converted to soluble, nearly colorless ammine compounds when the silver chloride is dissolved in ammonium hydroxide. In the case of platinum this ammine compound is very stable and does not react with the ordinary reagents used for the precipitation of platinum. It must, therefore, be decomposed by ignition at a temperature such as that of a pyrosulphate fusion.

\section{DETERMINATION OF IRIDIUM}

Most dental gold alloys that contain platinum also contain a small amount of iridium, usually not over 0.2 per cent. This iridium is probably not added intentionally, but is present as an impurity in the platinum that is used to make up the alloy. Alloys have been encountered that contained as much as 2 per cent of iridium, in which cases it probably was added intentionally.

When an alloy containing iridium, with gold as the predominant constituent, is dissolved in aqua regia, all of the iridium is left behind as an insoluble metallic residue, mixed with silver chloride if silver is present in the alloy. If platinum also is present in the alloy the insoluble residue of iridium may be contaminated with platinum. When the weight of the residue amounts to not more than 0.2 or 0.3 per cent of the sample, the amount of platinum that is with the iridium is so small that it may be neglected. When larger amounts of iridium are present it is usually necessary to separate the platinum in the residue from the iridium.

This behavior of iridium on dissolving the alloy in aqua regia has been verified by numerous experiments with alloys of known composition as well as in the analysis of a number of commercial alloys. The alloys ( 5 to $8 \mathrm{~g}$ for a charge) were made up from especially purified metals and melted in an Ajax-Northrup high-frequency induction furnace, using a crucible made of zirconium oxide. There was a melting loss ranging from a few tenths of a milligram in the alloys 
with no silver to 10 or $15 \mathrm{mg}$ in those alloys containing silver. This loss was ascertained to be chiefly silver and did not significantly change the percentage of iridium present. The buttons obtained from the melting were carefully cleaned and rolled out to a thin ribbon. The ribbon was cut into small pieces, a number of which were taken for the sample. The samples were decomposed with dilute aqua regia and the insoluble residue was filtered off. ${ }^{8}$ If silver chloride was present it was dissolved with ammonium hydroxicie as described under V, Determination of silver. The residue was ignited in a porcelain crucible, first in air to burn off the paper, and then in an atmosphere of hydrogen. The crucible was covered with a Rose lid of fused quartz fitted with a quartz delivery tube for the reduction of the partially oxidized iridium. The residue was weighed as metallic iridium.

The results of the analyses of these alloys are giren in Table 1.

TABLE 1.-Determination of iridium in alloys of known composition

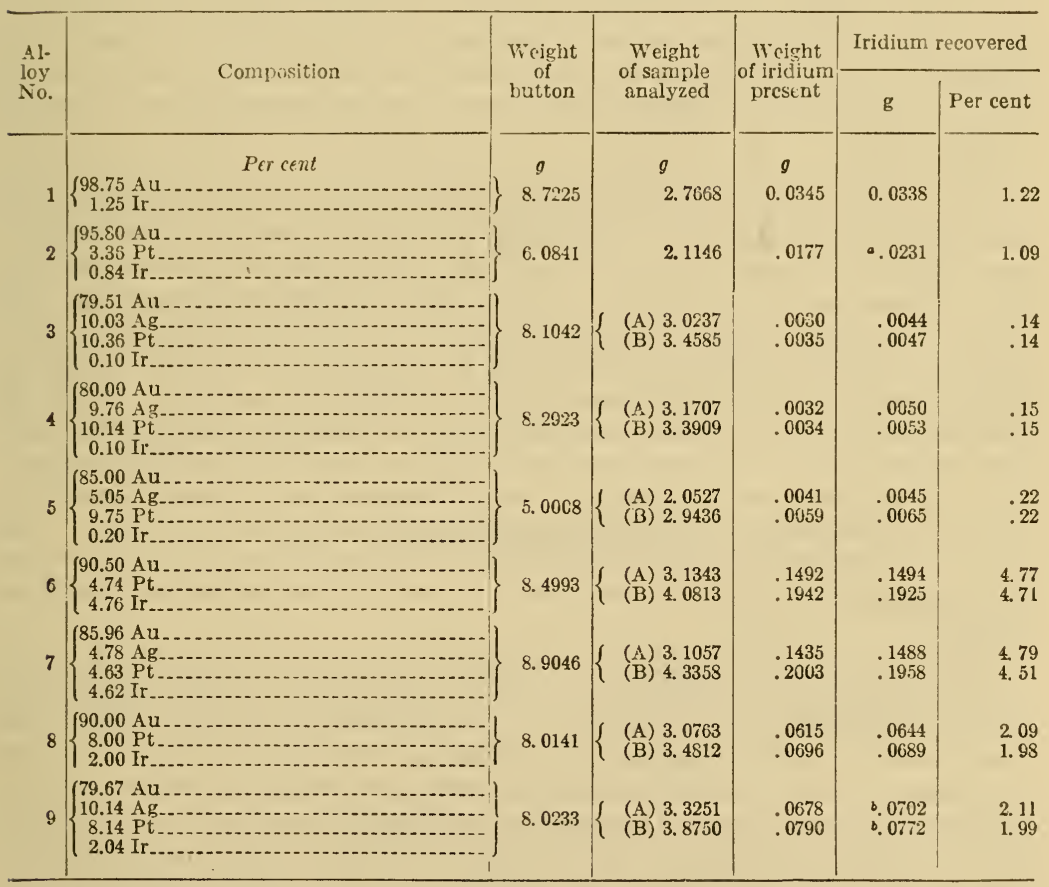

- This weight includes Pt, the amount of which was not determined by the method of fusion with lead. The weight of the insoluble residue from alloy No. 9 was: (A) $0.0841 \mathrm{~g}$; (B) $0.1032 \mathrm{~g}$. Pt in this residue was separated from the Ir by the method of fusion with lead, leaving the weight of iridium given.

6 In the preparation of these alloys, platinum and iridium were usually added to the gold as a platinumiridium alloy whose iridium content was known. In several instances the temperature had not been carried high enough for the gold to dissolve completely the platinum iridium alloy. The subsequent treatment of the gold alloy with aqua regia dissolved some of the iridium from the unalloyed platinumiridium. Hence if the alloy to be analyzed is not homogeneous, not all of the iridium will be obtained as an insoluble residue from the solution of the sample in aqua regia. 
When platinum was present in the alloy the weight of the insoluble residue was greater than the weight of iridium present in the sample. Each of these residues was examined qualitatively and found to contain platinum, but no silver or gold. No iridium was detected in any of the aqua regia solutions after the insoluble residue of iridium had been filtered off.

As stated before, when the alloy contains more than a few tenths of 1 per cent of iridium, the platinum contained in the insoluble residue from the solution of the sample in aqua regia should be separated from the iridum.

For this purpose the method described by Gilchrist ${ }^{7}$ for the determination of iridium in platinum alloys is recommended. The procedure given here, with the exception of a few minor changes, is quoted from the recommended procedure given in the above-mentioned paper.

Mix at least $5 \mathrm{~g}$ of granular test lead with the iridium-platinum residue and fuse the mixture for a period of one hour at a temperature of about $1,000^{\circ} \mathrm{C}$. A covered crucible machined from Acheson graphite is suitable for the fusion. The inside of the crucible should be conical with the apex at the bottom. The crucible is best heated in an electric furnace. Do not pour the fusion from the crucible, but allow it to solidify as the iridium has largely settled to the bottom of the crucible.

Brush the cooled lead button free from carbon with a camel's-hair brush and place it in a beaker. Add nitric acid of the concentration of 1 volume of acid (sp. gr. 1.42) to 4 volumes of water, using $1 \mathrm{cc}$ of concentrated acid per gram of lead. Place the beaker on the steam bath or on a hot plate which maintains the temperature of the solution at about $85^{\circ} \mathrm{C}$. Disintegration of the lead button is usually complete in about two hours, leaving a rather voluminous grayish-black mass. Dilute the solution to twice its volume and decant the liquid through a tight filter paper treated with filter-paper pulp. Wash the residue thoroughly with hot water and pass the washings through the filter. The residue is not transferred to the filter at this point. The lead nitrate solution and washings are best caught in an Erlenmeyer flask to make it easier to detect the presence of any residue which has passed through the filter. This is done by whirling the liquid in the flask. Any particles of the residue collect at the center of the bottom of the flask. Return the filter to the beaker without ignition.

Add, in order, $15 \mathrm{cc}$ of water, 5 ce of hydrochloric acid, and $1 \mathrm{ec}$ of nitric acid. Heat the solution in the beaker on the steam bath or on a hot plate which maintains the temperature at about $85^{\circ} \mathrm{C}$. The lead-platinum alloy is usually completely dissolved within one and one-half hours. Dilute the solution with twice its volume of water and filter through a tight paper, similar to the one used for the lead nitrate solution. The iridium, insoluble in aqua regia, is in the form of fine crystals, possessing a bright metallic luster and having a high density. Pass the clear solution through the filter first and then transfer the thoroughly macerated paper. It is very important to examine the beaker to see that no iridium remains. To do this the interior of the beaker is wiped with a piece of filter paper to collect any metal adhering to the sides. Then by whirling a small quantity of water in the beaker any iridium remaining gravitates toward

: Determination of Iridium in Platinum Alloys by the Method of Fusion with Lead, B. S. Sci. Papers, No. 483; also J. Am. Chem. Soc., 45, p. 2820; 1923. 
one place, whence it can be removed with a piece of paper. Wash the filter and iridium thoroughly with hot 1 per cent hydrochloric acid. The filtrate and washings containing the platinum should be examined for iridium, which may have passed through the filter, in the manner described under the nitric acid treatment. The last washings should be tested for the absence of lead.

Transfer the washed filter and iridium to a porcelain crucible and dry before igniting in air. After the destruction of the filter paper ignite the iridium strongly. After all carbon is burned out, cover the crucible with a Rose lid, preferably of fused quartz. Introduce into the erucible a stream of hydrogeu, burning from the tip of a Rose delivery tube (a quartz tube is preferred). After five minutes remove the burner and a few minutes later extinguish the hydrogen flame by momentarily breaking the current of hydrogen. This is best done by having a section of the rubber delivery tube replaced by a glass tube, one end of which can casily be disconnected. Allow the iridium to cool in an atmosphere of hydrogen and then weigh as metallic iridium.

This weight of iridium is subtracted from the weight of the insoluble iridium-platinum residue. The weight of platinum thus found is added to the weight of the main platinum precipitate obtained as directed under XI, Determination of platinum.

A direct determination of iridium can be made by the lead-fusion method. For this purpose the sample is fused with at least 10 times its weight of granulated test lead. The lead button is disintegrated with nitric acid of the concentration 1 volume of acid (sp. gr. 1.42) to 4 volumes of water, using $1 \mathrm{cc}$ of concentrated acid per gram of lead. The residue from the nitric acid solution is treated with aqua regia, using $15 \mathrm{cc}$ of water, $5 \mathrm{cc}$ of hydrochloric acid, and $0.8 \mathrm{cc}$ nitric acid for each gram of sample taken.

If silver is present it will be left as silver chloride mixed with the iridium residue. The silver chloride is separated from the iridium by dissolving it in ammonium hydroxide in the manner described under V, Determination of silver.

\section{DETERMINATION OF TIN}

For the complete analysis of a dental gold alloy it was necessary to devise a method by which tin could be completely precipitated from a solution containing both hydrochloric and nitric acids or their salts, and which would not interfere with the subsequent determination of the other constituents of the alloy.

It was found that if an excess of sodium acetate over the amount equivelent to the mineral acids present is added to the aqua regia solution of the alloy, the tin will be precipitated completely. The reaction is one of hydrolysis as the presence of the acetate suppresses the $\mathrm{H}$ ion concentration to the point where the hydrated stannic oxide is precipitated. The other constituents of the alloy, except iron, do not hydrolyze under these conditions. Fortunately iron is rarely present in a dental gold alloy in a sufficient amount to be significant. The tin precipitate can be filtered off quite easily, but 
it usually will be contaminated with small amounts of the metals in the mother liquor. However, by dissolving the first precipitate with sulphuric acid and reprecipitating as before, a second precipitate can be obtained free from the other metals that were present in the solution, except iron.

The precipitate is ignited to stannic oxide in a porcelain crucible and weighed. When necessary the amount of iron contained in the ignited residue can be determined and subtracted as oxide from the weight of the mixed oxides.

The procedure for the determination of tin is as follows: After silver chloride and iridium have been filtered off from the aqua regia solution of the sample, sodium acetate is added to the filtrate. Sixtenths of a gram of sodium acetate is added for each cc of dilute aqua regia used to dissolve the sample. When $25 \mathrm{cc}$ of dilute aqua regia is used, 45 cc of sodium acetate solution prepared as directed under III, Reagents, is added.

After the addition of the acetate, the solution is digested for an hour on the steam bath. The tin precipitate is filtered off on a $7 \mathrm{~cm}$ paper treated with filter-paper pulp. It is washed well with a hot 1 per cent solution of sodium chloride. Paper and precipitate are returned to the beaker and $5 \mathrm{cc}$ of sulphuric acid is added. After standing in the cold for a few minutes, the solution is heated on a hot plate, and nitric acid, a few drops at a time, is added until the paper is destroyed. The solution is then cooled, diluted with about $10 \mathrm{cc}$ of water, and filtered through a $51 / 2 \mathrm{~cm}$ paper. A little metallic gold is usually found on the paper. Paper and gold are ignited in a porcelain crucible. The residue is dissolved in a few cc of dilute aqua regia and the solution is added to the main solution of the sample before gold is precipitated.

The solution containing the tin is diluted to about $200 \mathrm{cc}$ and the tin is reprecipitated with ammonium acetate and digested for one hour on the steam bath.

Ammonium acetate instead of sodium acetate is used for the second precipitation because of the difficulty of washing out completely the mother liquor from the precipitate. The subsequent ignition of the precipitate, with ammonium salts present, avoids the error that would arise if alkali salts were present. Ammonium acetate can not be used for the first precipitation of tin because it would form ammonium chloroplatinate with the platinum that is usually present in the alloy.

When 5 cc of sulphuric acid is used to dissolve the first tin precipitate, $45 \mathrm{cc}$ of the ammonium acetate solution prepared as described under III, Reagents, will be sufficient to reprecipitate the tin. 
The precipitate is filtered off, washed with a hot 1 per cent solution of ammonium sulphate, and ignited in a porcelain crueible slowly until the paper is burned ofl, and finally over a blast lamp or Meker burner for about five minutes. The weight of tin is calculated from the weight of the stannic oxide residue.

All of the iron from the sample will be included in this residue. The color of the residue gives an indication as to the amount of iron present. Usually the amount is so small that it can be disregarded. When it is desired to make a separation, the amount of iron in the residue can be determined by a direct analysis of the mixture. The procedure is as follows: Transfer the weighed oxides of tin and iron to a small gold crucible. Add 2 or $3 \mathrm{~g}$ of solid sodium hydroxide and fuse the mixture for half an hour at a low red heat. Cool the melt, take up in water, and acidify with hydrochloric acid. A clear solution of all the tin and iron is obtained. Determine the iron in the solution by the usual colorimetric thiocyanate method. The details of this method may be found in any standard work on quantitative analysis. The presence of tin in the solution does not interfere with the iron determination. Subtract the weight of iron, calculated as $\mathrm{Fe}_{2} \mathrm{O}_{3}$, from the weight of tin and iron oxides first found. The weight of tin is then calculated from the corrected weight of stannic oxide.

The amount of iron contained in the sample may be calculated from the weight of iron as found above by subtracting from it the iron contained in the reagents that have been used in the analysis up to this point.

Results obtained with the above method of precipitating tin from solutions whose tin content was known, are given in Tables 2, 3 , and 4 .

In the first series of experiments, samples cut from a bar of pure tin ${ }^{8}$ were dissolved in aqua regia made up from $4 \mathrm{cc}$ of hydrochloric acid, $1 \mathrm{ec}$ of nitric acid, and $20 \mathrm{cc}$ of water. ${ }^{9}$ Thirty ec of ammoniumacetate solution (containing $10 \mathrm{~g} \mathrm{NH}_{4} \mathrm{C}_{2} \mathrm{H}_{3} \mathrm{O}_{2}$ ) were added to each

TABLE 2.-Precipitation of tin from a solution of pure tin

[Factor used is 0.7877]

\begin{tabular}{|c|c|c|}
\hline $\begin{array}{c}\text { Weight of pure tin } \\
\text { in grams }\end{array}$ & $\begin{array}{c}\text { Weight of } \\
\mathrm{SnO}_{2}\end{array}$ & $\begin{array}{c}\text { Calculated } \\
\text { as Sn }\end{array}$ \\
\hline & $g$ & $g$ \\
0.1356 & 0.1709 & 0.1346 \\
.1138 & .1141 & .113 .5 \\
1009 & .1011 \\
.1076 & .1284 & .1082 \\
\hline
\end{tabular}

- The tin used was cut from a bar of tin issued by the Bureau of Standards as a melting point standard and contained over 99.99 per cent tin.

-A qua regia was used to dissolve the tin to make the solution comparable to a solution of a dental gold alloy with respect to mineral acids

$101336^{\circ}-26-3$ 
solution. The precipitate was filtered off and ignited to stannic oxide $\left(\mathrm{SnO}_{2}\right)$. The results are given in Table 2 .

In the next series of experiments, iron from a standard iron solution was added to each sample of tin after it had been dissolved in dilute aqua regia. Tin and iron were precipitated together by means of ammonium acetate solution, filtered off, and ignited. The iron in the ignited residue was determined by the method described for this separation. The results are given in Table 3.

TABLE 3.-Precipitation of tin from a solution of tin and iron

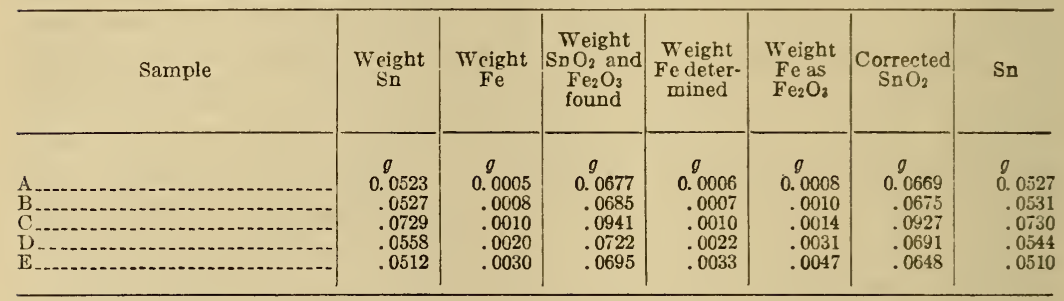

In the third series of experiments known weights of pure gold, platinum, and copper were added to the sample of pure tin. The mixture was dissolved in dilute aqua regia. Tin was precipitated with sodium acetate solution. The precipitate was filtered off, dissolved, and reprecipitated with ammonium acetate, according to the procedure already described. Gold, platinum, and copper were recovered from the filtrates by the methods ordinarily used for the determination of these metals in the analysis of a dental gold alloy. The results, given in Table 4 , show that the reagents used for the determination of tin do not interfere with the subsequent determination of the other metals in the alloy.

TABLE 4.-Precipitation of tin in the presence of gold, platinum, and copper

\begin{tabular}{|c|c|c|c|c|c|c|}
\hline \multirow{2}{*}{ Metal } & \multicolumn{2}{|c|}{ Sample A } & \multicolumn{2}{|c|}{ Sample B } & \multicolumn{2}{|c|}{ Sample C } \\
\hline & $\begin{array}{l}\text { Weight } \\
\text { added }\end{array}$ & $\begin{array}{l}\text { Weight } \\
\text { recovered }\end{array}$ & $\begin{array}{l}\text { Weight } \\
\text { added }\end{array}$ & $\begin{array}{c}\text { Weight } \\
\text { recovered }\end{array}$ & $\begin{array}{l}\text { Weight } \\
\text { added }\end{array}$ & $\begin{array}{l}\text { Weight } \\
\text { recovered }\end{array}$ \\
\hline $\begin{array}{l}\text { Sn } \\
\text { Au } \\
\text { Pt }\end{array}$ & $\begin{array}{l}g \\
0.0795 \\
.5655 \\
.7560 \\
.0759\end{array}$ & $\begin{array}{c}g \\
0.0802 \\
.5651 \\
.7567 \\
.0758\end{array}$ & $\begin{array}{r}9 \\
0.0795 \\
.6273 \\
.7576 \\
.0775\end{array}$ & $\begin{array}{c}g \\
0.0799 \\
.6274 \\
.7572 \\
.0781\end{array}$ & $\begin{array}{l}9 \\
0.0201 \\
.62 \leq 5 \\
.7584 \\
.0766\end{array}$ & $\begin{array}{r}g \\
0.0906 \\
.6253 \\
.7600 \\
.0780\end{array}$ \\
\hline
\end{tabular}

The solution of the sample, after the separation of $t$ in, is prepared for the determination of the gold. The filtrate from the first precipitation of the tin is eraporated to dryness on the steam bath. About 5 ce of sulphuric acid is added and the mixture is heated on the hot plate until fumes of sulphuric acid appear. This will eliminate 
all of the acetic acid and acetates. ('The presence of acetic acid retards the precipitation of gold with sulphur dioxide.) The residue is cooled and diluted with 15 to 20 ce of water. About 5 ce of a qua regia is added and the solution is heated on the steam bath until any metals precipitated by the treatment with sulphuric acid are aga in dissolved.

The filtrate from the second precipitation of the tin contains the netals except gold ${ }^{10}$ that contaminated the first tin precipitate. The solution must not be added to the first filtrate because the ammonium salts present would cause the precipitation of ammonium chloroplatinate. To recover the metals present, the solution is saturated with hydrogen sulphide. The small amount of sulphides thus obtained may contain copper, platinum, palladium, and zinc. The sulphides are filtered off, dissolved in a few cc of dilute aqua cegia, and the solution is added to the filtrate from the first precipitation of the tin. Nickel, if present, will be left in the filtrate from the sulphides, and is best precipitated with dimethylglyoxime, the precipitate being added to the main precipitate of nickel when that is obtained.

\section{DETERMINATION OF GOLD}

If a solution containing gold (the acidity of the solution may vary within a rather wide range) is saturated with sulphur dioxide, the gold will be precipitated quantitatively as metal. If platinum and palladium are present the precipitated gold will carry appreciable amounts of these metals and the gold must be reprecipitated. The impure precipitate is dissolved in aqua regia. The gold is reprecipitated from this solution with oxalic acid and is thus obtained free from platinum and palladium. Oxalic acid can not be used for the first precipitation of the gold in the presence of copper, because it would precipitate copper oxalate.

The extent to which platinum and palladium are carried down with the gold by the precipitation with sulphur dioxide was investigated. Six samples of an alloy containing gold, platinum, palladium, and copper were used. The gold was precipitated with sulphur dioxide and redissolved in dilute aqua regia. From this solution the gold was reprecipitated with oxalic acid, and the mother liquor was examined for platinum, palladium, and copper. The amounts of platinum and palladium that were recovered are given in Table 5 . Copper was not detected. No copper, platinum, or palladium was detected in the reprecipitated gold.

10 Directions have already been given in this section for the disposition of this small amount of gold. 
TABLE 5.-A mount of contamination of gold when precipitated by sulphur dioxide in the presence of platinum and palladium

\begin{tabular}{|c|c|c|c|c|c|}
\hline \multirow[t]{2}{*}{ Sample } & \multicolumn{3}{|c|}{$\begin{array}{l}\text { Weight of } \Lambda \mathrm{u}, \mathrm{Pt}, \text { and } \mathrm{P} d \mathrm{~d} \text { in each } \\
\text { sample }\end{array}$} & \multicolumn{2}{|c|}{$\begin{array}{l}\text { Weight of Pt and Pd re- } \\
\text { covered from filtrate } \\
\text { obtained by reprecip- } \\
\text { itating Au with ox- } \\
\text { alic acid }\end{array}$} \\
\hline & $A \mathrm{u}$ & $\mathrm{Pt}$ & $\mathrm{Pd}$ & $\mathrm{Pt}$ & $\mathrm{Pd}$ \\
\hline $\begin{array}{l}\text { A } \\
\text { B } \\
\text { C } \\
\text { D } \\
\text { E }\end{array}$ & $\begin{array}{r}0.7570 \\
0.7564 \\
1.1520 \\
1.1493 \\
.8669 \\
.8581\end{array}$ & $\begin{array}{l}\text { g. } \\
0.1640 \\
.1877 \\
.2495 \\
.2490 \\
.1878 \\
.1859\end{array}$ & $\begin{array}{l}g \\
0.0757 \\
.0866 \\
.1152 \\
.1150 \\
.0867 \\
.0858\end{array}$ & $\begin{array}{l}g \\
0.0103 \\
.0124 \\
.01122 \\
.01122 \\
.0094 \\
.0084\end{array}$ & $\begin{array}{l}g \\
0.0013 \\
.0073 \\
.0174 \\
.0151 \\
.0034 \\
.0045\end{array}$ \\
\hline
\end{tabular}

Two samples of another alloy containing gold and platinum among other metals, but no palladium, were also analyzed. The gold was precipitated with sulphur dioxide. dissolved in aqua regia, and reprecipitated with oxalic acid. See Table 6.

TABLE 6.-Amount of contamination of gold when precipitated by sulphur dioxide in the presence of platinum

\begin{tabular}{|c|c|c|c|}
\hline \multirow[b]{2}{*}{ Sample } & \multicolumn{2}{|c|}{$\begin{array}{l}\text { Weights of Au and Pt } \\
\text { in each sample }\end{array}$} & \multirow{2}{*}{$\begin{array}{l}\text { Weight of } \\
\text { Pt recov- } \\
\text { ered from } \\
\text { filtrate ob- } \\
\text { tained by } \\
\text { reprecipi- } \\
\text { tating Au } \\
\text { with ox- } \\
\text { alic acid }\end{array}$} \\
\hline & $\mathrm{Au}$ & $\mathrm{Pt}$ & \\
\hline 3. & $\begin{array}{l}\stackrel{g}{1.3576} \\
1.4316\end{array}$ & $\begin{array}{l}\stackrel{g}{ } \\
0.2026 \\
.2137\end{array}$ & $\begin{array}{l}g \\
0.0091 \\
.0067\end{array}$ \\
\hline
\end{tabular}

The detailed procedure for the determination of gold is as follows: If the alloy contains no tin the filtrate from the silver chloride is evaporated to dryness on the steam bath without waiting for the addition to it of the metals to be recovered from the filtrate left from the reprecipitation of the silver chloride. The residue is taken up with a little water followed by $10 \mathrm{cc}$ of hydrochloric acid. Most of the nitric acid will thus be driven off and sulphur dioxide will readily destroy the rest of it. If the alloy contains tin the filtrate from the precipitation of tin is prepared for the precipitation of the gold as previously described. In either case, the solution is diluted to about $200 \mathrm{cc}$. About $50 \mathrm{cc}$ of a saturated solution of sulphur dioxide in water is added and the solution is digested on the steam bath for about one hour. Additional sulphur dioxide solution (10 to $20 \mathrm{cc}$ ) is then added and the solution is set aside to cool. If the solution when cold still smells strongly of sulphur dioxide the precipitation of the gold is complete. The supernatant liquid is poured 
through a tight paper which has been treated with filter-paper pulp. The dark-colored precipitate is not transferred to the paper at this point, but is washed thoroughly in the beaker by decantation with a hot 1 per cent solution of hydrochloric acid. The paper is washed thoroughly and, together with the small amount of gold caught on it, is returned to the beaker. The filtrate should be examined for any gold that may have passed through the paper. If free from gold it is set aside for the next determination.

The impure precipitate is dissolved in $20 \mathrm{cc}$ of dilute aqua regia. The solution is filtered from the paper pulp, which is very thoroughly washed with hot 1 per cent hydrochloric acid. The solution is then eraporated to dryness on the steam bath. Two or three ce of hydrochloric acid is added and the solution is again evaporated to dryness. This is repeated twice, or until it is certain that all of the nitric acid has been eliminated. The precipitation of gold with oxalic acid is not complete in the presence of nitric acid. The residue is taken up with 5 cc of hydrochloric acid, 8 to 10 drops of sulphuric acid and 150 cc of water. Fifty cc of a saturated solution of oxalic acid is added and the solution is boiled for not more than 15 minutes. Prolonged boiling with oxalic acid will precipitate some of the platinum or palladium present. Ten cc more of the oxalic acid is added and the solution is boiled for a minute or two. If no further visible precipitation of gold takes place the solution is set on the steam bath for not less than four hours. The gold will be completely precipitated as a bright metallic sponge. It is filtered off on a paper that has been treated with filter-paper pulp. Great care must be taken to transfer all of the heavy gold particles from the beaker. The paper and the precipitate are ignited in a porcelain crucible and the residue is weighed as metallic gold.

The filtrate from the reprecipitation of the gold contains any platinum and palladium that were precipitated with the gold by sulphur dioxide. To recover the platinum and palladium the filtrate is evaporated to dryness, 5 cc of sulphuric acid is added to the residue and the mixture is again evaporated on the hot plate until nearly all of the sulphuric acid has been driven off. The oxalic acid will thus be eliminated. It is quite necessary to destroy the oxalic acid at this point as its presence in the solution would interfere with the subsequent determination of the copper.

The residue is digested with $10 \mathrm{cc}$ of dilute aqua regia until all of the precipitated metals are again dissolved. The solution is filtered off from any silica (from the glassware) and added to the filtrate from the first precipitation of the gold. 


\section{DETERMINATION OF PALLADIUM}

Silver, iridium, tin, and gold, if present, have now been separated and determined in the order named. Palladium is determined next. If the acid solution containing palladium is treated in the cold with an alcoholic solution of dimethylglyoxime, the palladium will be quantitatively separated as a flocculent yellow precipitate of palladium dimethylglyoxime. ${ }^{11}$ None of the constituents of a dental gold alloy except gold interferes with this precipitation. Hence, gold is removed first. The voluminous character of the precipitate makes it difficult to separate the mother liquor completely. When great accuracy is desired it is well to dissolve the first precipitate in nitric acid or in aqua regia and then reprecipitate the palladium with the same reagent. The filtrate from the reprecipitation usually contains 1 or $2 \mathrm{mg}$ of platinum.

The precipitate is either filtered on a Gooch crucible and the amount of palladium calculated from the weight of palladium dimethylglyoxime $\left(\mathrm{Pd} \mathrm{C}_{8} \mathrm{H}_{14} \mathrm{~N}_{4} \mathrm{O}_{4}\right)$ or it is ignited to metallic palladium and weighed as such. When the amount of palladium is small the first method is preferred.

The procedure for the determination of palladium is as follows: The metals recovered from the reprecipitation of the silver chloride as well as the platinum and palladium recovered from the reprecipitation of the gold, all dissolved in aqua regia, are added to the main solution containing the palladium; that is, the filtrate from the first precipitation of gold. This solution is evaporated to dryness on the steam bath. The residue is digested with $10 \mathrm{cc}$ of dilute aqua regia until all of it is in solution. It is diluted to about $250 \mathrm{cc}$ and cooled to room temperature. Enough of a 1 per cent solution of dimethylglyoxime in alcohol is added to precipitate all of the palladium. The solution must not be heated lest some of the platinum be precipitated. It requires $2.2 \mathrm{~g}$ of the solid reagent to precipitate $1 \mathrm{~g}$ of palladium. About 10 per cent over the theoretical amount is added.

After standing for one hour the precipitate is filtered off on a paper of suitable size and washed well with hot water. Additional reagent is added to the filtrate to ascertain whether or not all of the palladium has been precipitated. The precipitate with the paper is returned to the beaker and dissolved, on the steam bath, in 25 cc of dilute aqua regia. The paper pulp is filtered off, washed with hot water, and ignited in a porcelain crucible. Any metallic residue is dissolved in the crucible with a few cc of dilute aqua regia and the solution is added to the main solution of the palladium.

11 Davis, C. W., Separation of palladium and platinum by means of dimethylglyoxime, Bur. Mines Reports of Investigations, Serial No. 2351; May, 1922. 
This solution is diluted to about 250 ce and the palladium is precipitated as before. The precipitate is filtered on a Gooch crucible, washed thoroughly with hot water, dried at $110^{\circ} \mathrm{C}$., and weighed. The weight of the precipitate multiplied by 0.3167 gives the weight of palladium.

If the amount of palladium exceeds approximately $0.1 \mathrm{~g}$, the filtrintion of the precipitate on a Gooch crucible becomes very tedious and it may be filtered on a paper instead and ignited to metal. The ignition must be done with caution to prevent loss of palladium. After washing and allowing to drain, the paper with the precipitate is removed from the funnel and carefully wrapped in another ashless filter paper. The whole is placed in a porcelain crucible and dried at a temperature not exceeding $110^{\circ} \mathrm{C}$. The crucible is then covered with a Rose lid, and hydrogen is led in by means of a Rose delivery tube while the crucible is heated gently to decompose the compound. After this has been done, the Rose cover is removed and the paper is burned off in air. The residue is reduced to metallic palladium by heating strongly for several minutes in an atmosphere of hydrogen. The burner is then removed and the flame of the burning hydrogen is extinguished by momentarily interrupting the stream of hydrogen without removing the Rose lid from the crucible. The hydrogen is allowed to flow until the crucible has cooled to room temperature.

While cooling in the atmosphere of hydrogen the palladium sponge will absorb a good deal of the gas. Most of this can be removed by heating the crucible just to redness for a moment. This will partially oxidize the sponge, which will take on a purplish color. Then by heating the crucible on a hot plate and moistening the sponge from time to time with a few drops of formic acid the oxidized sponge is again reduced. The color of the fully reduced sponge is light gray.

The filtrates from the precipitation of palladium are united and evaporated to dryness. The excess of dimethylglyoxime is destroyed by adding about $5 \mathrm{cc}$ of nitric acid and digesting on the steam bath. The solution is again evaporated to dryness. The residue is then digested with $10 \mathrm{cc}$ of hydrochloric acid and enough water to dissolve the salts present.

\section{DETERMINATION OF COPPER}

Copper is determined in the filtrates from the precipitation of palladium. Usually it must be separated from platinum. This is done by precipitating the copper as cuprous thiocyanate. ${ }^{12}$ Although copper may be separated in this way from both palladium and

${ }_{12}$ Swanger and Wichers, The analytical separation of copper from the platinum metals, J. Am. Chem. Soc., 46, p. 1814; 1924. 
platinum and might be determined immediately after the precipitation of the gold with sulphur dioxide, palladium shows some tendency to contaminate the precipitate of cuprous thiocyanate. For this reason it is recommended that palladium be separated before the determination of copper is made.

The solution containing the copper and platinum is treated with sulphur dioxide. This treatment converts the platinum to a soluble sulphite. In this condition platinum does not form a precipitate with the ammonium thiocyanate that is used to precipitate the copper. The cuprous thiocyanate is filtered off and ignited and the residue is reduced to metallic copper.

The procedure is as follows: The filtrate from the precipitation of palladium, having been treated as described at the end of Section IX, Determination of palladium, is examined for any insoluble residue. Silica from the glassware and a small amount of an insoluble platinum compound are often present. They are filtered off on a small paper and ignited in a porcelain crucible. The residue is digested in the crucible with 3 or $4 \mathrm{cc}$ of dilute aqua regia and the solution is filtered from the silica and added to the main filtrate.

Fifty cc of a saturated solution of sulphur dioxide in water is added to the copper solution, which is then heated on the steam bath for about half an hour. The sulphur dioxide will reduce the copper to the cuprous condition and convert the platinum to sulphite. The solution is set aside to cool to room temperature. If it still has a strong odor of sulphur dioxide, the reduction may be considered complete. Otherwise more sulphur dioxide is added until an excess is present. The solution, diluted to about $300 \mathrm{cc}$, is just neutralized with sodium hydroxide. Ammonium hydroxide must not be used because it might cause the formation of ammine compounds of platinum. When the addition of 1 drop of sodium hydroxide solution causes a permanent cloudiness (precipitation of cuprous hydroxide), 8 to 10 drops of hydrochloric acid are added. The solution should now be clear and the odor of sulphur dioxide should be quite noticeable. Ammonium thiocyanate dissolved in saturated sulphur dioxide solution is added dropwise from a pipette with constant stirring. Ten cc of a 4 per cent solution of ammonium thiocyanate is sufficient to precipitate $100 \mathrm{mg}$ of copper. Usually $30 \mathrm{cc}$ is enough to precipitate all of the copper from a $2 \mathrm{~g}$ sample of a dental gold alloy.

The precipitate is allowed to settle for at least three or four hours. It is best to set the solution aside overnight to allow the precipitate to coagulate. The supernatant liquid will then be perfectly clear and of a light straw color. The precipitate should be pure white. If it is brown it is probably contaminated with platinum and should be reprecipitated. 
The precipitate is filtered off on a tight paper treated with filterpaper pulp. It is washed free from alliali salts with a cold 1 per cent solution of ammonium sulphate.

If the copper is to be reprecipitated, the paper and precipitate are returned to the beaker. 'The cuprous thiocyanate is decomposed by digesting it with $20 \mathrm{cc}$ of dilute nitric acid. The paper pulp is filtered off and ignited in a porcelain crucible. This will usually leave a small residue of copper and platinum which is dissolved in a few ce of dilute aqua regia. This solution is added to the main solution of the copper. The excess of nitric acid is evaporated off. The residue is taken up with 3 or 4 cc of hydrochloric acid and a little water. The solution is diluted to about $300 \mathrm{cc}$ and the copper is reprecipitated exactly as before. The precipitate is filtered off on a paper, as before, and washed free from alkali salts.

The paper and precipitate are placed in a porcelain crucible and dried at $110^{\circ} \mathrm{C}$. The crucible is covered with a Rose lid and hydrogen is led in by means of a Rose delivery tube. The crucible is then heated over a low flame of a Bunsen burner. When the cuprous thiocyanate has been completely broken up, the Rose lid is removed and the paper is burned off in air. The residue consists of copper oxide, the weight of which may be used to calculate the weight of copper. However, it is recommended that the oxide be reduced and cooled in hydrogen and weighed as metallic copper. If free from impurities, the resulting sponge will have a bright characteristic copper color.

\section{DETERMINATION OF PLATINUM}

The filtrate from the precipitation of copper is evaporated to dryness. The excess of thiocyanate is destroyed by adding 5 to $10 \mathrm{cc}$ of nitric acid and digesting the mixture on the steam bath for about half an hour. The solution is again evaporated to dryness. The nitric acid is completely expelled by heating the residue on the hot plate with 5 to $10 \mathrm{cc}$ of sulphuric acid until fumes of sulphuric acid appear. The residue is cooled and digested with $20 \mathrm{cc}$ of dilute hydrochloric acid. The solution is finally diluted to about $100 \mathrm{cc}$ and boiled to put all of the platinum compounds in solution. The solution will usually contain a small amount of silica. This is filtered off and ignited in a porcelain crucible. The residue is leached with dilute aqua regia to dissolve the small amount of platinum it usually contains. This solution is evaporated separately to expel the nitric acid and is then taken up with hydrochloric acid and added to the main solution containing the platinum.

This solution may now contain platinum, rhodium, nickel, zinc, manganese, magnesium, and, if the basic acetate separation for tin was not used, all of the iron. 
Hydrogen sulphide will precipitate platinum and rhodium quantitatively from this solution and will separate them from any of the above-named base metals that may be present. When rhodium is absent the precipitated sulphide is filtered off, ignited to metal, and weighed as platinum.

The precipitation of platinum by hydrogen sulphide takes place best in a solution containing some sulphuric acid. When hydrochloric acid alone is present, the sulphide has a tendency to stick to the sides of the beaker so that it can not be wiped off. When both acids are present, the beaker can be wiped out clean by using small pieces of moistened filter paper.

The warning may here be repeated that ammonium hydroxide must not be added to any of the solutions when platinum is present, and if ammonium salts are present the solution must not be made alkaline with sodium hydroxide. Free ammonia in a solution containing platinum will form soluble platinum ammines which can not be quantitatively precipitated by hydrogen sulphide. This was referred to under $V$, Determination of silver, and a method was given there for the recovery of the platinum from the ammine compounds.

The solution, having been treated to eliminate the excess of thiocyanate reagent, nitric acid, and nitrates as described abore, is diluted to about $300 \mathrm{cc}$. The acidity of the solution will range from 1 to $1.5 \mathrm{~N}$. A fairly rapid stream of hydrogen sulphide is passed through the solution for at least half an hour while it is heated to incipient boiling on the hot plate. The sulphide may be filtered off on a paper at once, as the precipitation is complete in the hot solution. The precipitate is washed thoroughly with hot 1 per cent hydrochloric acid. The filtrate is reserved for the next determination (see under XIII, Determination of zinc).

Paper and precipitate are placed in a porcelain crucible and ignited in air. The ignition is finished over the full heat of a Bunsen burner, to insure elimination of sulphur. The residual sponge is weighed as platinum (when rhodium is absent from the sample).

When great accuracy is desired in the determination of platinum, this ignited sponge is dissolved in $10 \mathrm{cc}$ of dilute aqua regia and the solution is evaporated to dryness on the steam bath. Nitric acid is expelled by adding 2 or $3 \mathrm{cc}$ of hydrochloric acid and repeating the evaporation to dryness. The residue is taken up with $20 \mathrm{cc}$ of dilute hydrochloric acid and 2 or 3 cc of sulphuric acid. The solution is diluted to about $300 \mathrm{cc}$ and the precipitation of the platinum with hydrogen sulphide is repeated. In this way any error due to the presence of alkali salts in the first precipitate is eliminated. 
If the insoluble residue left when the original sample was dissolved in aqua regia was treated for the separation of platinum from the iridium as described under VI, Determination of iridium, the weight of platinum thus found is added to the weight of the ignited sulphide above, to give the total weight of platinum.

\section{DETERMINATION OF RHODIUM}

In following the scheme of separations thus far outlined, rhodium, if present, is precipitated together with platinum as a mixture of sulphides after silver, iridium, tin, gold, palladium, and copper have been removed from the solution of the sample. The mixed sulphides are filtered off and ignited, first in air, then in hydrogen, and weighed as metallic platinum plus rhodium.

Separation of rhodium from the platinum is best made by the method described by Wichers. ${ }^{13}$ This method is based upon the hydrolysis of rhodium in a solution of platinum and rhodium chlorides using barium carbonate as the hydrolytic agent. The procedure is as follows: The weighed sponge of platinum and rhodium is transferred to a beaker and digested on the steam bath with 15 to $20 \mathrm{cc}$ of aqua regia. A little of the acid should be poured into the crucible in which the sponge was ignited to dissolve any metal adhering to the walls. The sponge generally dissolves completely. If there is a residue the solution is poured off and the residue is washed by decantation. Fresh portions of acid are added until it is certain that no more of the residue will dissolve. The residue may be considered to be rhodium. It is filtered off and ignited in the weighed porcelain crucible that is to be used for the determination of rhodium.

The solution of platinum and rhodium is evaporated nearly to dryness to expel most of the excess acids and is then diluted to about $200 \mathrm{cc}$. The free acid in the solution is neutralized with sodium hydroxide solution, using 4 to 8 drops of a 0.4 per cent solution of cresol red as indicator. The alkaline color of the indicator need not persist for more than a few seconds. A freshly prepared mixture consisting of $5 \mathrm{cc}$ of a solution containing $90 \mathrm{~g}$ of crystallized barium chloride per liter, and $5 \mathrm{cc}$ of a solution containing $36 \mathrm{~g}$ of anhydrous sodium carbonate per liter is added to precipitate the rhodium. After the suspension of barium carbonate is added the solution is rapidly heated to boiling and boiled for two minutes. The residue is filtered off, washed several times with a hot 2 per cent solution of sodium chloride, returned, together with the paper, to the beaker, and digested with $25 \mathrm{cc}$ of hydrochloric acid (1 volume of hydrochloric acid diluted with 4 volumes of water) until solution is complete. The

18 Edward Wichers, The analytical separation of rhodium from platinum, J. Am. Chem. Soc., 46. p. $1818 ; 1924$. 
presence of barium carbonate with the rhodium hydroxide may be noted by the evolution of carbon dioxide when the acid is added. If no barium carbonate is present the platinum-rhodium solution should be given a second treatment. If the first precipitate contains barium carbonate the filtrate may be acidified with hydrochloric acid and set aside for the subsequent recovery of platinum.

After the mixture of barium carbonate and rhodium hydroxide has dissolved in hydrochloric acid, the solution is diluted somewhat and filtered from the paper pulp. The solution is again treated with barium carbonate exactly as before. Care should be taken not to add an excess of sodium hydroxide in the preliminary neutralization. If the amount of rhodium present is very small, it is better to leave the solution slightly acid before adding barium carbonate. The period of boiling should be extended to three minutes. The precipitate is handled as before and a third precipitation made if desired. For mixtures of platinum and rhodium containing 1 per cent or less of rhodium, two precipitations should be sufficient, unless the first precipitate was for some reason unduly contaminated wtih platinum.

The final solution of rhodium chloride and barium chloride is diluted to about $150 \mathrm{cc}$. It contains about $5 \mathrm{cc}$ of hydrochloric acid. Rhodium is precipitated as sulphide by passing a fairly rapid stream of hydrogen sulphide for 30 to 45 minutes while the solution is heated to incipient boiling on the hot plate. The precipitated rhodium sulphide should be filtered off at once. If the solution is allowed to stand for some time after the precipitation is completed, some of the barium present may be converted to sulphate and be included with the rhodium sulphide. The precipitate is washed with a hot 1 per cent solution of ammonium chloride. The filtrate and wash water are discarded. The precipitate and paper are ignited in the crucible containing the insoluble residue from the solution of the mixed platinum-rhodium sponge. The ignited sulphide is finally reduced and cooled in an atmosphere of hydrogen, using a Rose lid and delivery tube. The residue is weighed as metallic rhodium. It should have a clean, light-gray color.

The weight of rhodium thus obtained is subtracted from the weight of the mixed sponge of platinum and rhodium to get the weight of platinum in the sample.

\section{DETERMINATION OF ZINC}

The solution of the sample, after the separation of platinum, or platinum and rhodium, as sulphide may contain one or more of the following metals: Zinc, nickel, manganese, magnesium, and also iron if not previously removed by the basic acetate method. Methods that are in general use for the determination of these base metals, 
and that may be found in any standard work on quantitative analysis, are applicable here. The methods given in this paper for the determination of these metals are those that were actually used in this laboratory for the analysis of a number of commercial dental gold alloys.

Zinc is determined by precipitating it with hydrogen sulphide from a solution which is $0.01 \mathrm{~N}$ with respect to sulphuric acid. ${ }^{14}$ The zinc sulphide is ignited to oxide and the amount of zinc is calculated from the weight of the oxide $(\mathrm{ZnO})$.

The solution, after filtering off the platinum sulphide (sulphides of platinum and rhodium, if rhodium is present) as described under XI, Determination of platinum, is evaporated to dryness on the steam bath. Chlorides and hydrochloric acid are eliminated by heating the residue on the hot plate until copious fumes of sulphuric acid are evolved. It may be necessary to add sulphuric acid. The residue is cooled and taken up with water. Any silica present is filtered off. The solution is neutralized with sodium or ammonium hydroxide, using methyl red as indicator. Enough standard sulphuric acid is then added to make the solution $0.01 N$ at a volume of about $350 \mathrm{cc}$. A rapid stream of hydrogen sulphide (at least eight bubbles per second) is passed through the solution at room temperature for half an hour. The zinc sulphide is allowed to settle for at least one hour. The precipitate is filtered off on a tight paper treated with filter-paper pulp. It is washed with a cold 1 per cent solution of ammonium sulphate, and ignited to oxide in a porcelain crucible. The paper is first charred, after which the carbon is slowly burned off. The residue is then carefully ignited, finishing at a temperature of not over $900^{\circ} \mathrm{C}$.

\section{DETERMINATION OF NICKEL}

Nickel is determined in the filtrate from the precipitation of zinc by the well-known Tschugaeff-Brunck method of preeipitation with dimethylglyoxime. The procedure is as follows: The filtrate from the precipitation of zinc is boiled to expel the hydrogen sulphide. One or two cc of sulphuric acid is added before the solution is heated to prevent the precipitation of nickel sulphide from the.hot, slightly acid solution. If any sulphur separates out during the boiling it is destroyed by adding bromine water until the solution has cleared up. The boiling is continued until most of the bromine has been expelled. Two or three cc of a saturated tartaric-acid solution are added to prevent the subsequent precipitation of iron with the nickel. Most of the excess acid is then neutralized with ammonium hydroxide. Enough of a 1 per cent solution of dimethylglyoxime in alcohol is added to the hot solution, which should be just barely acid, to pre-

14 F. G. Breyer, International Congress of Applied Chemistry. 25, p. 7; (1912.). 
cipitate all of the nickel. It requires $4 \mathrm{~g}$ of dimethylgloyxime to precipitate $1 \mathrm{~g}$ of nickel. About 10 per cent excess over the theoretical amount should be added. Enough ammonium hydroxide is then added to make the solution slightly ammoniacal. Care must be used not to have too much free ammonia present. The solution is set on the side of the steam bath for half an hour. The precipitate is then filtered off on a Gooch crucible, washed well with hot water, and dried at $110^{\circ} \mathrm{C}$. The weight of the precipitate multiplied by 0.2032 gives the weight of nickel.

Any nickel that may have been recovered from the reprecipitation of tin as described under VII, Determination of tin, is added to the main precipitate of nickel.

\section{DETERMINATION OF MANGANESE}

Manganese may be determined in the filtrate from the determination of nickel by oxidizing the manganese to permanganic acid with sodium bismuthate and titrating the permanganic acid with standard ferrous sulphate solution. The presence of interfering salts in the solution makes it necessary first to separate the manganese from the solution. To avoid this rather difficult separation it is recommended that manganese be determined in a separate sample. The procedure is as follows: The sample (about $0.5 \mathrm{~g}$ will usually be sufficient) is dissolved in $10 \mathrm{cc}$ of dilute aqua regia. The solution is evaporated to dryness and the residue is taken up with $5 \mathrm{cc}$ of hydrochloric acid and $50 \mathrm{cc}$ of water. Without previously filtering off the silver chloride, hydrogen sulphide is passed through the solution for half an hour while it is heated to incipient boiling on the hot plate. The sulphides of copper, platinum, gold, etc., are filtered off and discarded.

The filtrate is evaporated to dryness. About 5 cc of sulphuric acid is added and the solution is heated on the hot plate until copious fumes of sulphuric acid are evolved. The residue is cooled, the sides of the beaker are washed down with water, and the solution is again heated until most of the sulphuric acid has been evaporated. The residue is taken up with $50 \mathrm{cc}$ of nitric acid (sp. gr. 1.135) and the solution is boiled to expel oxides of nitrogen. The solution is cooled, and $0.5 \mathrm{~g}$ of sodium bismuthate (free from manganese) is added. The solution is then heated until the pink color of the permanganate disappears and a precipitate of manganese dioxide has formed. More of the bismuthate is added if manganese dioxide does not precipitate. The solution is cleared by adding a few drops of a saturated solution of sodium bisulphite or other suitable reducing agent that is free from chlorides. Oxides of nitrogen and sulphur are expelled by boiling. The solution is cooled to $15^{\circ} \mathrm{C}$. and an excess of sodium bismuthate is again added, the solution is agitated, and let stand for a few minutes. The solution is diluted with $50 \mathrm{cc}$ of 3 per cent 
nitric acid (free from nitrous acid) and filtered through asbestos. The residue is washed with 3 per cent nitric acid until the washings run through colorless. Three ec of phosphoric acid (sp. gr. 1.71) are added to the combined filtrate and washings to destroy the color due to any iron that may be present. The solution is titrated with standardized ferrous sulphate and potassium permanganate solutions.

\section{DETERMINATION OF IRON}

The determination of iron is rarely necessary in the complete analysis of a dental gold alloy. If it is required, a separate sample should be used. The sample (about $0.5 \mathrm{~g}$ ) is dissolved in $10 \mathrm{cc}$ of dilute aqua regia. The hydrogen sulphide metals and silver chloride are remored in the same way as directed for the manganese determination. The filtrate is boiled to expel the hydrogen sulphide. Two or three ec of nitric acid are added, and the solution is boiled to oxidize the iron to the ferric condition. The iron is precipitated by adding an excess of ammonium hydroxide. The precipitate of ferric hydroxide is filtered off and ignited to ferric oxide. The weight of iron is calculated from the weight of the ferric oxide $\left(\mathrm{Fe}_{2} \mathrm{O}_{3}\right)$.

In an alloy containing tin, a determination of iron will already have been made in the process of purification of the tin precipitate as directed under VII, Determination of tin, and another determination of iron will not be necessary.

If the amount of iron in the solution is too small to be determined grarimetrically, it may be determined by a colorimetric method using thiocyanate as the reagent. This method is in such general use that it is not considered necessary to give the details here.

\section{DETERMINATION OF MAGNESIUM}

Magnesium is rarely present in a dental gold alloy. A separate sample should be taken for the determination. As the amount of magnesium will usually be small, not less than $1 \mathrm{~g}$ of sample should be used. The magnesium is precipitated as magnesium ammonium phosphate according to the method of B. Schmitz. Thesolution of the alloy must be freed from all of the other metals before magnesium is precipitated. The procedure is as follows: The sample is dissolved in 15 cc of dilute aqua regia. The metals precipitable by hydrogen sulphide in acid solution are removed along with the silver chloride as described under XV, Determination of manganese. The filtrate is transferred to an Erlenmeyer flask and the free acid is neutralized with ammonium hydroxide. Two or three cc excess of ammonium hydroxide are added. Hydrogen sulphide is again passed into the cold solution to saturation, whereby manganese, nickel, zinc, and iron are precipitated. A second like amount of 
ammonium hydroxide is now added. The flask, filled to the neck and corked, is set aside for at least 12 hours. The precipitate is then filtered off. The filtrate containing the magnesium is evaporated to about $100 \mathrm{cc}$ and acidified slightly with hydrochloric acid. Any sulphur that separates out is destroyed by adding bromine water and boiling. The boiling is continued until most of the excess bromine is expelled.

The slightly acid solution, having a volume of not over $100 \mathrm{cc}$, is heated to boiling and treated with an excess of sodium or ammonium phosphate or microcosmic salt (10 per cent solutions). Ammonium hydroxide is then added, drop by drop, with constant stirring, until the solution is alkaline. A volume of ammonium hydroxide (sp. gr. 0.96) equal to one-third of the volume of the magnesium solution is then added. The solution is cooled and the precipitate is allowed to settle for at least two hours. The precipitate is filtered off on a paper, washed with an ammonium hydroxide solution containing 50 cc of ammonium hydroxide per liter, and ignited to magnesium pyrophosphate. The amount of magnesium is calculated from the weight of the ignited residue.

\section{RESULTS OF ANALYSES OF A NUMBER OF ALLOYS}

The results of 13 analyses made according to the methods described in this paper are given in Table 7 . The analyses were made in duplicate and the composition of the alloy was reported as the average of the two determinations of each constituent giving the percentage to one decimal place, except when the amount of the constituent was less than 1 per cent, in which case the percentage was given to two decimal places. In the table all of the results are given to two decimal places for purposes of comparison only. 
TABLE 7.-Complete analyses of typical dental gold alloys.

\begin{tabular}{|c|c|c|c|c|c|c|c|c|c|c|c|c|c|}
\hline Alloy & Sample & $\mathrm{Ag}$ & Ir & Sn & $\mathrm{Au}$ & $\mathrm{Pd}$ & $\mathrm{Cu}$ & $\mathrm{Pt}$ & $\mathrm{Rh}$ & $\mathrm{Zn}$ & $\mathrm{Ni}$ & Fo & Total \\
\hline 1 & A & $\begin{array}{l}\text { Per } \\
\text { cent } \\
7.14 \\
7.12\end{array}$ & $\begin{array}{c}\text { Per } \\
\text { cent } \\
0.15 \\
.13\end{array}$ & $\begin{array}{c}\text { Per } \\
\text { cent } \\
0.82 \\
.81\end{array}$ & $\begin{array}{c}\text { Per } \\
\text { cent } \\
71.31 \\
71.25\end{array}$ & $\begin{array}{c}P_{\ell r} \\
\text { cent }\end{array}$ & $\begin{array}{l}P_{e t} \\
\text { cent } \\
9.86 \\
9.90\end{array}$ & $\begin{array}{c}\text { Per } \\
\text { ecnt } \\
10.65 \\
10.59\end{array}$ & $\begin{array}{l}\text { Per } \\
\text { cent }\end{array}$ & $\begin{array}{c}\text { Per } \\
\text { cent } \\
0.08 \\
.07\end{array}$ & $\begin{array}{c}\text { Per } \\
\text { cent }\end{array}$ & $\begin{array}{l}\text { Pcr } \\
\text { cent }\end{array}$ & $\begin{array}{c}\text { Per } \\
\text { cent } \\
99.87 \\
100.01\end{array}$ \\
\hline 2 & $\int A$ & ...... & $\begin{array}{l}\text { 1. } 23 \\
\text { 1. } 21\end{array}$ & & $\begin{array}{l}75.60 \\
75.55\end{array}$ & $\begin{array}{l}16.07 \\
16.04\end{array}$ & 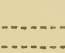 & $\begin{array}{l}6.95 \\
6.97\end{array}$ & & $\begin{array}{r}.06 \\
.07\end{array}$ & & & $\begin{array}{l}99.91 \\
99.84\end{array}$ \\
\hline 3 & & $\begin{array}{l}.09 \\
.08\end{array}$ & & & $\begin{array}{l}90.60 \\
90.84\end{array}$ & 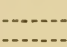 & . & $\begin{array}{l}9.31 \\
9.33\end{array}$ & & $\begin{array}{l}.02 \\
.02\end{array}$ & $\begin{array}{r}0.01 \\
.01\end{array}$ & & $\begin{array}{r}100.03 \\
99.98\end{array}$ \\
\hline 1 & & $\begin{array}{l}9.31 \\
9.35\end{array}$ & $\begin{array}{l}.3 k \\
.41\end{array}$ & & $\begin{array}{l}62.23 \\
62.37\end{array}$ & $\begin{array}{l}.45 \\
.53\end{array}$ & $\begin{array}{l}4.52 \\
\text { 4. } 49\end{array}$ & $\begin{array}{l}23.00 \\
22.64\end{array}$ & & $\begin{array}{l}.09 \\
.08\end{array}$ & $\begin{array}{l}.02 \\
.02\end{array}$ & $\begin{array}{r}0.15 \\
.15\end{array}$ & $\begin{array}{l}100.15 \\
100.04\end{array}$ \\
\hline 5 & & $\begin{array}{l}\text { 4. } 97 \\
\text { 4. } 94\end{array}$ & $\begin{array}{l}.15 \\
.15\end{array}$ & & $\begin{array}{l}63.91 \\
63.91\end{array}$ & $\begin{array}{l}10.20 \\
10.22\end{array}$ & $\begin{array}{l}\text { 7. } 12 \\
\text { 7. } 13\end{array}$ & $\begin{array}{l}13.49 \\
13.43\end{array}$ & & $\begin{array}{l}.18 \\
.18\end{array}$ & & & $\begin{array}{r}100.02 \\
99.96\end{array}$ \\
\hline 6 & & $\begin{array}{l}10.98 \\
11.00\end{array}$ & $\begin{array}{l}.23 \\
.24\end{array}$ & $\begin{array}{l}.13 \\
.12\end{array}$ & $\begin{array}{l}60.41 \\
60.43\end{array}$ & $\begin{array}{l}5.89 \\
5.86\end{array}$ & $\begin{array}{l}\text { 8. } 83 \\
8.80\end{array}$ & $\begin{array}{l}12.90 \\
12.99\end{array}$ & & $\begin{array}{l}.72 \\
.71\end{array}$ & & & $\begin{array}{l}100.09 \\
100.15\end{array}$ \\
\hline 7 & $1 A$ & $\begin{array}{l}5.98 \\
6.02\end{array}$ & & & $\begin{array}{l}71.42 \\
71.37\end{array}$ & & $\begin{array}{l}\text { 15. } 59 \\
\text { 15. } 53\end{array}$ & $\begin{array}{l}2.73 \\
2.83\end{array}$ & & $\begin{array}{l}2.36 \\
2.39\end{array}$ & $\begin{array}{l}1.99 \\
1.97\end{array}$ & & $\begin{array}{l}100.07 \\
100.11\end{array}$ \\
\hline 8 & & $\begin{array}{l}5.88 \\
5.95\end{array}$ & $\begin{array}{l}.03 \\
.03\end{array}$ & & $\begin{array}{l}65.76 \\
65.89\end{array}$ & $\begin{array}{l}\text { 5. } 73 \\
5.70\end{array}$ & $\begin{array}{l}10.02 \\
10.16\end{array}$ & $\begin{array}{l}10.60 \\
10.87\end{array}$ & $\begin{array}{r}0.61 \\
.50\end{array}$ & $\begin{array}{l}\text { 1. } 35 \\
\text { 1. } 33\end{array}$ & & & $\begin{array}{r}99.83 \\
100.43\end{array}$ \\
\hline 9 & & $\begin{array}{l}\text { S. } 31 \\
\text { 8. } 39\end{array}$ & 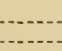 & .18 & $\begin{array}{l}83.31 \\
83.29\end{array}$ & & $\begin{array}{l}\text { 8. } 33 \\
\text { 8. } 29\end{array}$ & & & & & & 100.1 \\
\hline 10 & & $\begin{array}{l}9.67 \\
9.65\end{array}$ & $\begin{array}{l}.07 \\
.07\end{array}$ & & $\begin{array}{l}66.34 \\
66.34\end{array}$ & $\begin{array}{l}7.79 \\
7.76\end{array}$ & $\begin{array}{l}\text { 12. } 94 \\
12.94\end{array}$ & $\begin{array}{l}\text { 2. } 04 \\
\text { 2. } 08\end{array}$ & & $\begin{array}{l}\text { 1. } 18 \\
1.19\end{array}$ & $\cdots$ & & $\begin{array}{l}100.03 \\
100.03\end{array}$ \\
\hline 11 & $\left\{\begin{array}{l}\mathrm{A} \\
\mathrm{B}\end{array}\right.$ & $\begin{array}{l}11.67 \\
11.65\end{array}$ & & & $\begin{array}{l}67.77 \\
67.80\end{array}$ & & $\begin{array}{l}10.55 \\
10.54\end{array}$ & $\begin{array}{l}\text { 10. } 13 \\
10.12\end{array}$ & & & & & $\begin{array}{l}100.12 \\
100.11\end{array}$ \\
\hline 12 & & & & & $\begin{array}{l}75.61 \\
75.63\end{array}$ & & $\begin{array}{l}10.64 \\
10.60\end{array}$ & $\begin{array}{l}10.18 \\
10.10\end{array}$ & & $\begin{array}{l}1.12 \\
1.04\end{array}$ & $\begin{array}{l}2.71 \\
2.74\end{array}$ & & $\begin{array}{l}109.25 \\
100.11\end{array}$ \\
\hline 13 & & $\begin{array}{l}.22 \\
.19\end{array}$ & $\begin{array}{l}.46 \\
.50\end{array}$ & & $\begin{array}{l}66.23 \\
66.27\end{array}$ & $\begin{array}{l}19.41 \\
19.46\end{array}$ & $\begin{array}{l}.23 \\
.21\end{array}$ & $\begin{array}{l}\text { 13. } 31 \\
13.32\end{array}$ & & $\begin{array}{l}.10 \\
.14\end{array}$ & & & $\begin{array}{r}99.93 \\
160.09\end{array}$ \\
\hline
\end{tabular}

\section{ACKNOWLEDGMENT}

The author wishes to acknowledge his indebtedness to Dr. Edward Wichers, chemist at the Bureau of Standards, under whose direction this work was carried out, and who aided in the preparation of the manuscript for publication.

Washington, April 30, 1926. 



